\title{
NILAI TAMBAH KERIPIK PISANG PADA INDUSTRI RUMAH TANGGA IBU DEWI (Studi Kasus Kecamatan Malalayang)
}

\author{
Wahyudi Mokodongan \\ Juliana R. Mandei \\ Joachim N. K. Dumais
}

\begin{abstract}
ABSRACT
This study aims to determine the amount of: (1) the cost per one time production, (2) revenue and income per one time production (3) added value from the banana processing business into banana chips. This research was conducted in Kecamatan Malalayang. Data collection begins at the end of February to March 2017. Data collection methods are conducted using primary data. Primary data was obtained through interviews based on a prepared list of questions, as well as on-site observations. The data collected involves: The variable cost is the amount of value influenced by the amount of production of banana chips is the cost of raw materials (bananas) and the cost of fuel (kerosene, LPG gas), Fixed costs consist of: depreciation cost of equipment and construction depreciation or cost other beyond the variable cost. Depreciation is the cost of depreciation per year, ie stove, knife, spoon of fryers, chopper, scales, and trays per year. Additives material are ingredients other than the main ingredients needed in the production process ie cooking oil, sugar, salt, egg yolk, and wrapping plastic. The total cost is all costs incurred in the production of bananas into banana chips. Methods of data analysis conducted in this study are: (1) calculate the total cost per one time production, (2) calculate the business profits processing banana fruit into banana chips per one time production with the formula $\pi=T R$ - TC. (3) Calculating the added value of the banana processing business into banana chips. The results showed that (1) The amount of cost the banana Dewi chips per production is Rp. 164.000, - with details of banana raw material Rp. 25.000, - and auxiliary materials, among others, cooking oil, sugar, salt, egg yolks cendrawasih, plastic wrapping, and gas Rp. 139.000, -. (2) Large income and income per one time banana banana chips production is 20 packs per one time production with selling price Rp. 20.000, - so the revenue of Dewi banana chips is 400,000, - and (3) the amount of added value from the processing of banana into Dewi banana chips is Rp. 232.555,48 and for the value added to the raw material of banana chips, 232.555.48 divided by 100 bananas the result is 2,325,55, meaning that each banana that is processed into banana chips can give the addition of value of 2,325,55.
\end{abstract}

Keywords: value added, banana chips, home industry, Kecamatan Malalayang, Manado City

\section{ABSTRAK}

Penelitian ini bertujuan untuk mengetahui besarnya: (1) biaya per satu kali produksi, (2) penerimaan dan pendapatan per satu kali produksi (3) nilai tambah dari usaha pengolahan pisang menjadi keripik pisang. Penelitian ini dilakukan di Kecamatan Malalayang. Pengambilan data dimulai pada akhir bulan Februari sampai bulan Maret 2017. Metode pengumpulan data dilakukan dengan menggunakan data primer. Data primer diperoleh melalui wawancara dengan pihak bersangkutan berdasarkan daftar pertanyaan yang telah disiapkan, serta pengamatan langsung di lapangan. Data yang dikumpulkan menyangkut: Biaya variabel yaitu biaya yang jumlah nilai dipengaruhi oleh jumlah produksi keripik pisang adalah biaya bahan baku (pisang) dan biaya bahan bakar (minyak tanah, gas elpiji), Biaya tetap terdiri dari: biaya penyusutan peralatan dan penyusutan bangunan atau biaya lainnya diluar biaya variabel. Biaya penyusutan adalah biaya yang disusutkan per tahun, yaitu kompor, pisau, sendok serokan, alat perajang, timbangan, serta nampan per tahun. Bahan tambahan adalah bahan selain bahan utama yang dibutuhkan dalam proses produksi yaitu minyak goreng, gula, garam, kuning telurm plastik pembungkus, dan gas. Biaya total adalah seluruh biaya yang dikeluarkan dalam produksi pisang menjadi keripik pisang. Metode analisis data yang dilakukan dalam penelitian ini adalah: (1) menghitung biaya per satu kali produksi, (2) menghitung keuntungan usaha pengolahan buah pisang menjadi keripik pisang per stu kali produksi dengan rumus $\pi=$ TR TC. (3) Menghitung nilai tambah dari usaha pengolahan pisang menjadi keripik pisang. Hasil penelitian menunjukkan bahwa (1) Besarnya biaya sekali produksi keripik pisang Dewi yaitu Rp. 164.000,- dengan rincian bahan baku pisang Rp. 25.000,- dan bahan penolong antara lain, minyak goreng, gula, garam, cendrawasih kuning telur, plastik pembungkus, dan gas Rp. 139.000,-. (2) Besar penerimaan dan pendapatan per satu kali produksi keripik pisang Dewi yaitu 20 bungkus per satu kali produksi dengan harga jual Rp. 20.000,- jadi besar penerimaan keripik pisang Dewi adalah 400.000,- dan (3) besarnya nilai tambah dari usaha pengolahan pisang menjadi keripik pisang Dewi adalah Rp. 232.555,48 dan untuk besarnya nilai yang ditambahkan pada bahan baku keripik pisang, maka 232.555.48 dibagi dengan 100 buah pisang hasilnya 2.325,55, artinya untuk setiap buah pisang yang diolah menjadi kripik pisang dapat memberikan penambahan nilai sebesar 2.325,55

Kata kunci: nilai tambah, keripik pisang, industri rumah tangga, Kecamatan Malalayang, Kota Manado 


\section{PENDAHULUAN}

\section{Latar Belakang}

Sektor pertanian mempunyai peran yang sangat besar pada pertumbuhan ekonomi negara terutama negera yang bercorak agraris seperti Indonesia. Pembangunan ekonomi menitik beratkan pada bidang pertanian dan industri yang berbasis pertanian atau bisa disebut agroindustri. Dalam sistem agribisnis, agroindustri adalah salah satu subsitem yang bersama-sama subsistem lain membentuk agribisnis. Sistem agribisnis terdiri dari subsistem input (agroindustri hulu), usahatani (pertanian), sistem output (agroindustri hilir), pemasaran dan penunjang. Dengan demikian pembangunan agroindustri tidak dapat dilepaskan dari pembangunan agribisnis secara keseluruhan. Pembangunan agroindustri akan dapat meningkatkan produksi, harga hasil pertanian, serta dapat menghasilkan nilai tambah hasil pertanian (Masyuri, 1994). Peran sektor agroindustri dalam perekonomian nasional difokuskan pada nilai pengganda output, nilai tambah, tenaga kerja dan keterkaitan antar sektor serta perannya dalam meningkatkan pendapatan rumah tangga. Apabila upah tenaga kerja diasumsikan merupkan suatu konstanta yang bersifat konstan dalam satu titik waktu, maka nilai tambah tenaga kerja dapat dijadikan sebagai stimulus penyerapan tenaga kerja nasional, sementara peran sektor agroindustri dalam meningkatkan pendapatan sektor lain dapat ditingkatkan melalui pengganda keterkaitan sektor, khususnya keterkaitan ke belakang.

Pembangunan agroindustri dengan bahan baku yang tersedia dalam jumlah dan waktu yang sesuai, merupakan syarat kecukupan untuk berproduksi secara berkelanjutan. Optimalisasi nilai tambah dicapai pada pola industri yang berintegrasi langsung dengan usahatani keluarga dan perusahaan pertanian. Usaha agroindustri "keripik pisang" termaksud kedalam agroindustri makanan dengan bahan baku utama pisang merupakan usaha tradisional yang banyak dilakukan masyarakat dan telah berkembang sejak lama di Manado, Sulawesi Utara. Usaha ini telah dilakukan turun temurun. Keripik pisang ibu DEWI adalah salah satu produk industri kecil yang ada di Manado Sulawesi Utara, keripik pisang DEWI meniliki nilai tambah karena tidak menggunakan kapur sirih untuk menjaga kerenyahan keripik pisang karena kapur sirih akan membuat rasa alami dari keripik pisang berkurang, ibu DEWI menggunakan cendrawasih kuning telur untuk kerenyahan keripik pisang dan menjaga rasa alami dari keripik pisang tersebut. Keripik pisang DEWI termaksud industri berskala kecil dengan tenaga kerja yang terbatas, keripik pisang yang dihasilkan dijual dengan cara online. Berdasarkan ulasan diatas peneliti tertarik untuk meneliti nilai tambah dari keripik pisang DEWI yang ada di Manado Sulawesi Utara.

\section{Tujuan Penelitian}

1. Mengetahui besarnya biaya per satu kali produksi

2. Mengetahui besarnya penerimaan dan pendapatan per satu kali produksi

3. Mengetahui besarnya nilai tambah dari usaha pengolahan pisang menjadi keripik pisang

\section{Manfaat Penelitan}

1. Bagi peneliti. Dapat dijadikan sebagai tambahan pengalaman dan pengetahuan, disamping untuk melengkapi salah satu persyaratan guna memperoleh gelar Sarjana Pertanian Universitas Sam Ratulangi.

2. Bagi pihak lain. Diharapkan hasil penelitian ini nantinya dapat berguna sebagai tambahan informasi maupun pengetahuan.

\section{METODE PENELITIAN}

\section{Tempat dan waktu}

Penelitian ini dilakukan di kec malalayang, pemilihan lokasi penelitian ini ditentukan secara sengaja (purposive), dengan dasar pertimbangan bahwa lokasi tersebut merupakan salah satu daerah sentra penghasil pisang sebagai bahan baku serta banyak industri rumah tangga yang bergerak pada agroindustri kripik pisang. Pengambilan data dimulai pada akhir bulan februari sampai maret.

\section{Metode Pengumpulan Data}

Metode pengumpulan data dilakukan dengan menggunakan data primer. Data primer 
diperoleh melalui wawancara dengan pihak bersangkutan berdasarkan daftar pertanyaan yang telah disiapkan, serta pengamatan langsung di lapangan.

\section{Konsepsi Pengukuran Variabel}

Pada penelitian ini konsepsi pengukuran variabel yang digunakan adalah sebagi berikut

1. Bahan baku adalah bahan utama yaitu buah pisang yang diolah menjadi produk ( $\mathrm{Kg} /$ proses produksi)

2. Biaya variablel adalah biaya yang jumlah nilai dipengaruhi oleh jumlah produksi keripik pisang, seperti :

a. biaya bahan baku (pisang)

b. biaya bahan bakar (minyak tanah, gas elpiji)

3. Biaya tetap adalah biaya yang jumlahnya tidak tergantung pada jumlah produksi keripik. Terdiri dari :

a. biaya penyusutan peralatan

b. penyusutan bangunan atau biaya lainnya diluar biaya variabel.

4. Biaya penyusutan adalah biaya yang disusutkan setiap tahun, dimana alat atau mesin semakin lama semakin turun kemampuan serta efisiensinya.

5. Bahan tambahan adalah bahan selain bahan utama yang dibutuhkan dalam proses produksi.

6. Biaya total adalah seluruh biaya yang dikeluarkan dalam produksi pisang menjadi keripik pisang

\section{Metode Analisis Data}

Metode analisis data yang dilakukan dalam penelitian ini adalah:

1. Menghitung keuntungan usaha pengolahan buah pisang menjadi keripik pisang.

Keterangan :

Rumus: $\pi=\mathrm{TR}-\mathrm{TC}$

$\pi=$ keuntungan usaha pengolahan buah pisang menjadi keripik pisang

$\mathrm{TR}=$ penerimaan usaha pengolahan buah pisang menjadi keripik pisang ( $\mathrm{Rp})$

$\mathrm{TC}=$ biaya total usaha pengolahan buah pisang menjadi keripik pisang (Rp)

Untuk biaya total dapat dihitung dengan menggunakan rumus sebagai berikut:

$$
\text { Rumus: } \mathrm{TC}=\mathrm{TFC}+\mathrm{TVC}
$$

Keterangan:

$\mathrm{TC}=$ Biaya total usaha pengolahan buah pisang menjadi keripik pisang (Rp)

TFC = biaya tetap usaha pengolahan buah pisang menjadi keripik pisang ( $\mathrm{Rp})$

TVC = biaya variabel usaha pengolahan buah pisang menjadi keripik pisang ( $\mathrm{Rp})$

Untuk menghitung penerimaan dapat diitung dengan menggunakan rumus sebagai berikut:

Keterangan:

$$
\text { Rumus: TR }=\mathrm{Q} \times \mathrm{P}
$$

$\mathrm{TR}=$ penerimaan total usaha pengolahan buah pisang menjadi keripik pisang $(\mathrm{Rp})$

$\mathrm{P}=$ harga produk keripik pisang $(\mathrm{Rp})$

$\mathrm{Q}=$ jumlah produk keripik pisang (bungkus)

2. Analisis nilai tambah

$$
\text { Rumus : } \begin{aligned}
\mathrm{NTp}=\mathrm{Na} & -(\mathrm{Bb}+\mathrm{Bp}+\mathrm{Bbp}) \\
& =\mathrm{Na}-\mathrm{Ba}
\end{aligned}
$$

Keterangan :

NTp = Nilai tambah produk $(\mathrm{Rp})$

$\mathrm{Na}=$ Nilai produk akhir $(\mathrm{Rp})$

$\mathrm{Ba}=$ biaya antara $(\mathrm{Rp})$

$\mathrm{Bb}=$ biaya bahan baku

$\mathrm{Bp}=$ biaya penyusutan alat $(\mathrm{Rp})$

$\mathrm{Bbp}=$ biaya bahan penolong $(\mathrm{Rp})$

\section{HASIL DAN PEMBAHASAN}

Gambaran Umum Usaha Keripik Pisang Usaha keripik pisang Ibu Dewi berlokasi di Kelurahan Malalayang 1 manibang Kecamatan Malalayang Sulawesi Utara. Usaha ini dijalankan awal mula bergerak tahun 2016. Industri ini mengelola pisang menjadi keripik pisang. Bahan baku untuk pembuatan keripik pisang dibeli dari penjual pisang dengan harga 25.000 per 100 buah pisang, sekali produksi Ibu Dewi memakai 100 buah pisang yang dibeli dari warga sekitar yang memiliki kebun. Produksi keripik pisang ibu dewi tidak menggunakan tenaga kerja melainkan hanya dibantu oleh suami dan ibunya. Pemasaran keripik pisang ibu dewi dilakukan secara online melalui sosisal media yaitu facebook, dan untuk pengantar di kenakan biaya tambahan sesuai jarak pengantaran. 


\section{Penggunaan Peralatan}

Pengadaan peralatan yang tepat dapat membantu melancarkan proses kegiatan produksi serta dapat memberikan keuntungan bagi usaha keripik pisang Dewi. Biaya penggunaan peralatan pada usaha keripik pisang Dewi selama proses produksi, dapat dilihat pada Tabel 1.

Tabel 1. Biaya penggunaan peralatan usaha keripik pisang Dewi

\begin{tabular}{cccc}
\hline Jenis Alat & $\begin{array}{c}\text { Jumlah } \\
\text { (unit) }\end{array}$ & $\begin{array}{c}\text { Harga } \\
\text { pembelian } \\
\text { (Rp) }\end{array}$ & $\begin{array}{c}\text { Nilai sisa } \\
\text { (Rp) }\end{array}$ \\
\hline Kompor & 1 & 150000 & 2000 \\
Wajan & 1 & 75000 & 3000 \\
Pisau & 2 & 10000 & 500 \\
Serok & 1 & 2000 & 0 \\
Alat & 1 & 150000 & 0 \\
Perajang & & & \\
Timbangan & 1 & 180000 & 0 \\
Nampan & 2 & 15000 & 0 \\
\hline
\end{tabular}

Tabel 1 memperlihatkan total biaya penggunaan yang di keluarkan oleh usaha pengolahan keripik pisang Dewi di Kecamatan Malalayang.

Tabel 2. Nilai penyusutan penggunaan peralatan usaha keripik pisang dewi

\begin{tabular}{ccc}
\hline \multicolumn{3}{c}{ Umur ekonomis } \\
\hline Bulan & $\begin{array}{c}\text { Proses } \\
\text { produksi }\end{array}$ & Penyusutan alat (Rp) \\
\hline 60 & 240 & 616,67 \\
36 & 144 & 500,00 \\
24 & 96 & 203,13 \\
24 & 96 & 20,83 \\
36 & 144 & $1.041,67$ \\
60 & 240 & 750,00 \\
24 & 96 & 312,50 \\
\hline Jumlah & & $\mathbf{3 . 4 4 4 , 7 9}$ \\
\hline
\end{tabular}

Tabel 2 memperlihatkan nilai penyusutan pada peralatan usaha keripik pisang, nilai penyusutan kompor pertahun 616,67, wajan 500,00, pisau 203,13, serok 20,83, alat perajang $1.041,67$, timbangan 750,00 , serta nampan 312,50 pertahun.

\section{Penyediaan Bahan Baku Dan Bahan Penolong}

Bahan baku utama yang digunakan dalam proses pengolahan keripik pisang adalah pisang. Bahan baku adalah bahan mentah yang diolah untuk menghasilkan produk pertanian dengan nilai yang lebih tinggi. Ketersediaan bahan baku secara stabil dan berkelanjutan dapat membantu proses produksi suatu usaha berjalan lancar dan usaha dapat beroperasi dalam waktu relatif lama. Selain bahan baku ada juga bahan penujang atau bahan penolong lain yang dipakai produksi keripik pisang Dewi, bahan penolong yang dipakai adalah minyak goreng, gula, garam, cendrawasih kuning telur, plastik pembungkus, dan gas. Bahan baku yang dipakai dalam proses produksi keripik pisang Dewi adalah pisang yang di beli dari warga pengepul dengan harga 250 ,- per buah.

\begin{tabular}{|c|c|c|c|c|}
\hline No & Jenis Bahan & Jumlah Satuan & $\begin{array}{c}\text { Harga } \\
\text { (Rp/Satuan) }\end{array}$ & $\begin{array}{c}\text { Jumlah } \\
\text { Biaya } \\
\text { (Rp) }\end{array}$ \\
\hline A & $\begin{array}{l}\text { Bahan Baku } \\
\text { Utama }\end{array}$ & & & \\
\hline 1 & Pisang & Buah & 250 & $25.000,-$ \\
\hline Jumlah & & & & 25.000 ,- \\
\hline \multirow[t]{2}{*}{ A } & Bahan Penolong & & & \\
\hline & Bahan Penolong & Kuantitas & $\begin{array}{c}\text { Harga } \\
(\mathbf{R p})\end{array}$ & $\begin{array}{l}\text { Total } \\
(\mathbf{R p})\end{array}$ \\
\hline 1 & Minyak Goreng & $5 \mathrm{Kg}$ & $12.000,-$ & $6.000,-$ \\
\hline 2 & Gula & $1 \mathrm{Kg}$ & $12.000,-$ & $12.000,-$ \\
\hline 3 & Garam & \multirow{2}{*}{$\begin{array}{c}250 \mathrm{Kg} \\
15 \mathrm{ml}\end{array}$} & $2.000,-$ & $2.000,-$ \\
\hline 4 & $\begin{array}{l}\text { Cendrawasih } \\
\text { Kuning Telur }\end{array}$ & & $2.500,-$ & $5.000,-$ \\
\hline 5 & $\begin{array}{c}\text { Plastik } \\
\text { Pembungkus }\end{array}$ & 1 tol & $40.000,-$ & $40.000,-$ \\
\hline 6 & Gas & $3 \mathrm{Kg}$ & $20.000,-$ & $20.000,-$ \\
\hline Jumlah & & & & $\begin{array}{c}130.000, \\
-\end{array}$ \\
\hline Total & & & & $\begin{array}{c}164.000, \\
-\end{array}$ \\
\hline
\end{tabular}

Tabel 3 merupakan rincian penggunaan biaya bahan baku dan bahan penolong yang diperlukan dalam proses produksi keripik pisang Dewi, dimana biaya bahan penolong yaitu minyak goreng menjadi biaya terbesar dalam proses produksi dengan jumlah 60.000 dan untuk biaya terendah yaitu garam sebesar 2000. Jumlah keseluruhan biaya bahan baku dan bahan penolong adalah sebesar 164.000. total biaya yang dikeluarkan dari proses produksi ini dapat dilihat pada Tabel 3.

Tabel 4. Total Biaya pengolahan keripik Pisang pada usaha Keripik Pisang Dewi

\begin{tabular}{lll}
\hline No & Uraian & Jumlah (Rp) \\
\hline 1 & Biaya Tetap & \\
& Biaya Penyusutan Peralatan & $3.444,79$ \\
2 & Biaya Variabel & \\
& Biaya Bahan Baku & $25.000,-$ \\
& Biaya Bahan Penolong & $139.000,-$ \\
\hline Total Biaya & $\mathbf{1 6 7 . 4 4 4 , 7 9}$ \\
\hline
\end{tabular}

Tabel 4 memperlihatkan biaya-biaya yang ada dalam pengolahan keripik pisang 
Dewi, jumlah biaya tetap adalah 3.444,79 dan jumlah biaya variabel adalah sebesar 164.000. total biaya dari biaya tetap dan biaya variabel adalah $167.444,79$

\section{Penerimaan Usaha Keripik Pisang Dewi}

Penerimaan usaha keripik pisang Dewi diperoleh dari perkalian antara harga jual keripik pisang dalam pasar perdagangan dengan jumlah keripik yang diproduksi oleh keripik pisang Dewi. Jumlah produksi keripik pisang Dewi yaitu 20 bungkus sekali produksi dengan harga jual 20.000 maka besar penerimaan kotor usaha keripik pisang Dewi adalah 400.000

\section{Analisis Nilai Tambah Keripik Pisang Dewi}

Pehitungan analisis nilai tambah usaha pengolahan pengolahan keripik pisang Dewi dilakukan untuk mengetahui besarnya nilai yang ditambahkan pada bahan baku yang digunakan yaitu pisang dan perhitungan analisis nilai tambah keripik pisang adalah sebagai berikut :

Perhitungan Analisis Nilai Tambah (Rp) :

$$
\begin{aligned}
\mathrm{NTp} & =\mathrm{Na}-(\mathrm{Bb}+\mathrm{Bp}+\mathrm{Bbp}) \\
& =\mathrm{Na}-\mathrm{Nb} \\
& =400.000-(25.000+3.444,79+139.000) \\
& =400.000-167.444 \\
& =232.555 .48
\end{aligned}
$$

Berdasarkan perhitungan tersebut nilai tambah yang didapat dari usaha ini adalah $\mathrm{Rp}$. 232.555,48 dan untuk besarnya nilai yang ditambahkan pada bahan baku keripik pisang, maka 232.555.48 dibagi dengan 100 buah pisang hasilnya $2.325,55$, artinya untuk setiap buah pisang yang diolah menjadi kripik pisang dapat memberikan penambahan nilai sebesar 2.325,55. Hasil analisis menunjukan bahwa keripik pisang Dewi memiliki prospek yang baik karena produk keripik pisangnya memiliki nilai tambah.

\section{KESIMPULAN DAN SARAN}

\section{Kesimpulan}

Besarnya biaya sekali produksi keripik pisang Dewi yaitu Rp. 164.000,- dengan rincian bahan baku pisang Rp. 25.000,- dan bahan penolong antara lain, minyak goreng, gula, garam, cendrawasih kuning telur, plastik pembungkus, dan gas Rp. 139.000,-. Besar penerimaan dan pendapatan per satu kali produksi keripik pisang Dewi yaitu 20 bungkus persekali produksi dengan harga jual Rp. 20.000,- jadi besar penerimaan keripik pisang Dewi adalah 400.000,- dan besarnya nilai tambah dari usaha pengolahan pisang menjadi keripik pisang Dewi adalah Rp. 232.555,48 dan untuk besarnya nilai yang ditambahkan pada bahan baku keripik pisang, maka 232.555.48 dibagi dengan 100 buah pisang hasilnya $2.325,55$, artinya untuk setiap buah pisang yang diolah menjadi kripik pisang dapat memberikan penambahan nilai sebesar 2.325,55

\section{Saran}

Kepada keripik pisang Dewi agar dapat memproduksi keripik pisang setiap hari, dan untuk penjualan keripik pisang agar dapat berkembang perlu dimasukkan ke supermarket agar pendapatannya lebih besar.

\section{DAFTAR PUSTAKA}

Djuwari. 1994. Aspek-aspek Ekonomi Usaha Tani. Program Pasca Sarjana. UGM. Yogyakarta.

Gasperz, V. 1999. Ekonomi Manajerial Pembuatan Pembuatan Keputusan Bisnis. PT Gramedia. Jakarta.

Hanafi, M. M. 2004. Manajemen Keuangan. Fakultas Ekonomi. UGM. Yogyakarta.

Lipsey, G. R. Peter, O. S. \& Douglas, D. P. 1990. Pengantar Mikroekonomi 1 Jilid I. Diterjemahkan oleh Jaka, A. W dan Kirbrandoko. Erlangga. Jakarta.

Mahadewi, H. 2002. Analisis Usaha Agroindustri Lanting di Kabupaten Kebumen. Skripsi S1 Fakultas Pertanian UNS. Surakarta. 
Makki, M. F. et al. 2001. Nilai Tambah Agroindustri pada Sistem Agribisnis Kedelai di Kalimantan Selatan. Dalam Jurnal Agroekonomika. No 1. Juli 2001.

Masyhuri. 1994. Pengembangan Agroindustri Melalui Penelitian Pengembangan Produk yang Intensif dan Berkesinambungan dalam Journal Agro Ekonomi Vol VII/ No. 1 Juni/ 2000. Jurusan Sosial Ekonomi Pertanian. Fakultas Pertanian UGM. Yogyakarta.

Nicholson, W. 1992. Mikroekonomi Intermediate Dan Penerapannya. Erlangga. Jakarta.

Purba, R. 1986. Manajemen Manunggal Bagi Wiraswasta. Pustaka Dian. Jakarta.

Soekartawi. 1990. Teori Ekonomi Produksi Dengan Pokok-pokok Bahasan Analisis Fungsi Cobb-Douglas. Rajawali. Jakarta.
Soekartawi, Rusmadi, Effi D. 1993. Resiko dan Ketidakpastian Dalam Agribisnis : teori dan aplikasi. Cetakan Pertama. PT Raja Grafindo Persada. Jakarta.

Soekartawi. 1995. Analisis Usaha Tani. UI Press. Jakarta.

Suryana, A. 2005. Arah, Strategi dan Program Pembangunan Pertanian 2005-2009. Badan Penelitian dan Pengembangan Pertanian. Departemen Pertanian. Jakarta.

Tarigan, R. 2004. Ekonomi Regional. Bumi Aksara. Jakarta.

Todaro, M. P. 1994. Pembangunan Ekonomi Dunia Ketiga Jilid 2. Erlangga. Jakarta. 